\title{
RBEP
}

\section{Ações afirmativas no ensino superior: análise do perfil socioeconômico e da experiência universitária de bolsistas do ProUni na PUC-Rio}

Clarissa Tagliari Santos

\section{Resumo}

Analisa a inserção universitária de beneficiados pelo Programa Universidade para Todos (ProUni) na Pontifícia Universidade Católica do Rio de Janeiro (PUC-Rio). De iniciativa do governo federal, o ProUni tem como objetivo ampliar o acesso da população de baixa renda à educação superior brasileira. A amostra de pesquisa incluiu estudantes ingressantes de três cursos dessa universidade no período de 2005 a 2010. A partir de questionários e entrevistas, buscou-se traçar o perfil socioeconômico dos alunos beneficiados e apresentar os principais incentivos e dificuldades para a permanência. Os resultados sugerem que o programa funcionou como um mecanismo positivo de inclusão na instituição de grupos historicamente excluídos da educação superior, mas alertam para a importância de mecanismos que garantam a conclusão do curso.

Palavras-chave: ações afirmativas; ensino superior; Programa Universidade para Todos. 


\section{Abstract \\ Affirmative action in higher education: an analysis of the socio- -economic profile and university experience of the students benefited from the ProUni scholarships at the PUC- Rio University}

This study analyses the integration of the students benefited from the University for All Program (ProUni) into the Pontifícia Universidade Católica do Rio de Janeiro (PUC-Rio). The ProUni is sponsored by the brazilian government and has the goal of expanding the access of low-income population to higher education in Brazil. The research sample included freshmen from 2005 to 2010 of three courses of PUC-Rio. The socio-economic profile of these students and the main difficulties and incentives to stay in the university were outlined from questionnaires and interviews. The results indicate that the program acted as a positive mechanism for the inclusion in the university of groups historically excluded from higher education, although stresses the importance of mechanisms to ensure the graduation of the benefited population.

Keywords: affirmative action; higher education; University for All Program.

\section{Introdução}

As ações afirmativas entram em pauta na agenda pública brasileira por ocasião da III Conferência Mundial contra o Racismo, a Discriminação Racial, a Xenofobia e a Intolerância, organizada e realizada no ano de 2001, em Durban, África do Sul, pela Organização das Nações Unidas (ONU). A ideia era de que seus países membros adotassem medidas que revertessem as desigualdades produzidas por discriminações de qualquer tipo.

Tendo em vista os objetivos dessa Conferência, o governo de Fernando Henrique Cardoso nomeia uma comissão que, alicerçada em estudos sobre as enormes desigualdades entre brancos e não brancos no acesso a educação, saúde e renda, como os de Carlos Hasenbalg, Nelson do Valle e Silva e Ricardo Henriques, produz um relatório final apontando as ações afirmativas como indispensáveis para romper o ciclo de reprodução das desigualdades raciais no Brasil (Brandão, 2007).

Certamente, a implementação de ações afirmativas no ensino superior público e, mais especificamente, a adoção de políticas de cotas nas universidades públicas do País ocupam um lugar de destaque tanto no que diz respeito às polêmicas em torno dessas medidas compensatórias como no que se refere à produção acadêmica sobre o tema. Várias pesquisas 
estão sendo realizadas avaliando o desempenho, inserção e relações interraciais entre os estudantes cotistas e não cotistas nessas instituições (Santos, 2005; Brandão, 2007; Peixoto, Aranha, 2008). Ao contrário do que se verifica no setor público, a experiência universitária dos bolsistas do Programa Universidade para Todos (ProUni) nos estabelecimentos privados ainda não mereceu, por parte dos pesquisadores e da mídia do País, atenção proporcional à magnitude do programa, que já atendeu cerca de 600 mil estudantes entre 2005 e 2009.

Institucionalizado em 2005 pela Lei $\mathrm{n}^{\circ}$ 11.096, o ProUni tem como finalidade a concessão de bolsas de estudo integrais e parciais para estudantes de baixa renda em cursos de graduação e sequenciais de formação específica nas instituições de ensino superior (IES) privadas. O programa insere-se também no contexto de estratégias do governo federal para expansão deste nível de ensino de forma a cumprir as metas do Plano Nacional de Educação (PNE), que pretendia aumentar a taxa líquida da educação superior para 30\% até 2010.

De fato, apesar da expansão das matrículas experimentada nos últimos anos, frequentam curso superior atualmente apenas 13,9\% dos jovens brasileiros na faixa etária entre 18 e 24 anos (IBGE, 2009), proporção esta que coloca o Brasil entre os últimos países do mundo em termos de cobertura do ensino superior, mesmo em comparação a nossos vizinhos da América Latina. O caráter extremamente desigual deste sistema se revela de forma mais clara quando comparamos as oportunidades de ingresso dos diferentes grupos sociais: no Brasil, filhos de profissionais têm quatro vezes mais chances de entrar na universidade do que filhos de trabalhadores rurais, enquanto os estudantes brancos têm de duas a três vezes mais chances do que os não brancos (Pastore, Silva, 2000).

O ProUni é criado, então, como uma alternativa para aumentar a oferta de ensino superior gratuito sem comprometer o orçamento do Ministério da Educação (MEC), ao mesmo tempo em que estimula as instituições privadas a destinarem suas vagas aos grupos historicamente excluídos deste nível de ensino. No próprio memorando de apresentação e justificativa do projeto de lei do ProUni (Brasil, 2004) são apresentados dados demonstrando o aumento da demanda por ensino superior entre 1998 e 2002 e a existência de aproximadamente meio milhão de vagas ociosas nas instituições privadas.

As instituições com fins lucrativos e sem fins lucrativos não beneficentes que aderem ao programa recebem, em contrapartida, isenção de alguns impostos. A adesão das instituições beneficentes de assistência social, por sua vez, é obrigatória. Dessa forma, o ProUni teria ainda a vantagem de dar transparência e servir como uma forma de controle público sobre as instituições que já possuíam isenções garantidas constitucionalmente (Ristoff, 2006).

Os critérios para o aluno se inscrever no programa são: a) não possuir diploma de ensino superior; b) ter obtido no Exame Nacional do Ensino Médio (Enem) nota mínima de 45 pontos; ${ }^{1}$ c) possuir renda familiar mensal per capita de até um salário mínimo e meio para obtenção de

\footnotetext{
${ }^{1}$ Desde 2009, devido à adoção do Enem no processo seletivo de algumas instituições públicas, houve várias mudanças na estrutura e conteúdo desta prova, sendo necessário atualmente atingir uma nota mínima de 400 pontos (média das cinco notas obtidas nas provas do Exame) para concorrer a uma bolsa do Programa.
} 
bolsas integrais e de até três salários mínimos para bolsas parciais; e d) ter estudado o ensino médio em escolas públicas ou em escolas privadas na condição de bolsista (Brasil, 2005).

O ProUni reserva ainda parte das bolsas às pessoas com deficiência física, aos pretos, pardos e indígenas, desde que se enquadrem nos critérios de seleção acima citados. Também os professores da rede pública de ensino básico podem concorrer a bolsas do programa em cursos de licenciatura, normal superior ou pedagogia. Neste caso, a renda familiar não é considerada.

Ao contrário das controvérsias surgidas a partir da adoção de ações afirmativas nas universidades públicas, que versaram sobre o caráter democratizador ou ameaçador das políticas de cotas para as relações raciais no País, a criação do ProUni foi acompanhada de intenso debate sobre o sentido privatista dado à expansão da educação superior e sobre as concessões feitas ao setor privado ao longo do processo de elaboração legal do programa. Os artigos produzidos logo nos dois primeiros anos de vigência do ProUni que abordaram tais questões também chamavam a atenção para a necessidade de divulgação de informações sobre a quantidade de bolsas ofertadas por cada IES e em quais cursos e para a importância de pensar não apenas o acesso, mas também a garantia da permanência dos bolsistas (Carvalho, 2006; Catani, Hey, Gilioli, 2006).

A avaliação e o aprimoramento de qualquer política que pretenda contribuir para o avanço da igualdade de oportunidades dependem tanto da disponibilização de informações como do acompanhamento de seus beneficiários. No entanto, ainda hoje se sabe muito pouco sobre os impactos do ProUni para a democratização do ensino superior. Praticamente, nada se sabe sobre a inserção destes bolsistas nestas instituições e suas condições de estudo, ou mesmo sobre números e causas da evasão - e essa ausência não existe apenas na esfera governamental, mas também no que diz respeito à produção acadêmica sobre o tema.

Diante desta realidade, esta pesquisa pretende conhecer de forma mais detalhada quem são os bolsistas que logram entrar na melhor universidade privada do País (Retratos..., 2009) em três cursos de alto prestígio social (Administração, Direito e Psicologia) e como se processa a experiência universitária desses bolsistas. Qual o perfil individual e familiar dos alunos beneficiados? Em que medida eles se diferenciam do alunado da PUC-Rio? Quais as principais dificuldades acadêmicas e não acadêmicas enfrentadas? Qual é o papel da instituição e o de outras redes de apoio na inserção desses bolsistas? Essas são algumas questões a serem respondidas neste trabalho.

\section{Alguns aspectos sobre o ProUni na PUC-Rio}

A PUC-Rio é uma universidade de natureza privada beneficente sem fins lucrativos; portanto, sua adesão ao ProUni foi automática. Segundo dados fornecidos pela Vice-Reitoria para Assuntos Comunitários e pela 
Vice-Reitoria Acadêmica da instituição, o corpo discente da PUC-Rio, no primeiro semestre de 2010, era constituído por 12.912 alunos de graduação. Desse total, 58\% não possuíam nenhum tipo de bolsa ou financiamento, 1.003 estudantes eram beneficiados pelo ProUni (todos com bolsas integrais) e 145 recebiam bolsa Ação Social, programa de bolsas da própria IES voltado para jovens de baixa renda. Esse reduzido número de bolsistas de Ação Social é explicado pela necessidade da instituição em atender às exigências legais da oferta de bolsas ProUni, tendo, para tanto, diminuído, ao longo dos últimos anos, a concessão de bolsas de Ação Social (Rodrigues, 2008). Os demais estudantes participavam de outros programas de bolsas e financiamentos, como a Bolsa Acadêmica, a Bolsa PUC e o Fundo de Financiamento ao Estudante de Ensino Superior (Fies).

No que diz respeito à sua distribuição nas diversas carreiras oferecidas pela instituição, os bolsistas do ProUni estão alocados principalmente nas áreas de maior prestígio social e acadêmico, como as Engenharias, Comunicação Social, Direito e Administração; já as carreiras relacionadas à licenciatura apresentam um número reduzido de bolsistas (Gráfico 1). ${ }^{2}$

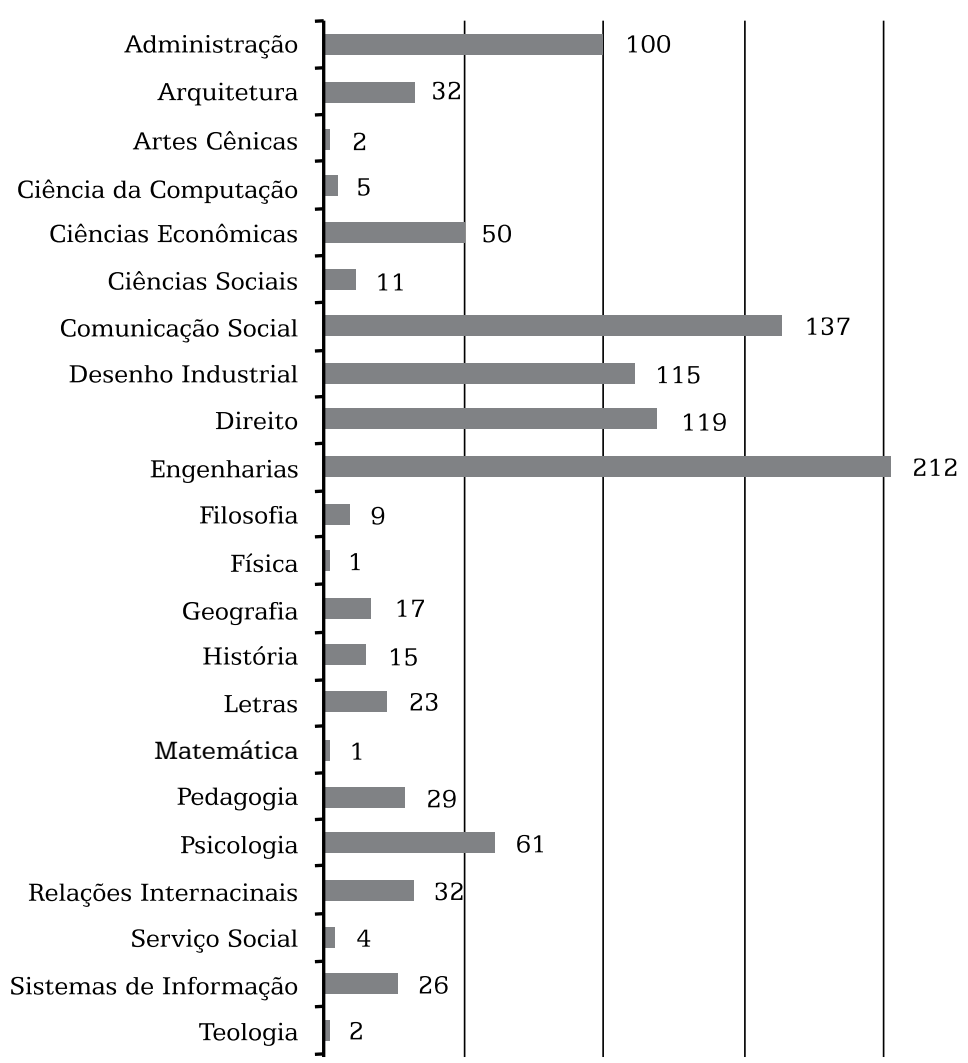

Gráfico 1 - Número de Bolsistas ProUni segundo o Curso na PUC-Rio

Como mostra Faceira (2009), o ProUni teve um impacto importante sobre a lógica de filantropia da PUC-Rio. A autora, ao analisar a implementação do programa nessa universidade, constata que, se antes a alocação
${ }^{2} \mathrm{O}$ elevado número de bolsas, por exemplo, nas Engenharias e em Comunicação Social, deve-se à existência de várias habilitações nessas carreiras. 
das bolsas de estudos para alunos mais pobres ocorria nas graduações das Licenciaturas e de Serviço Social, o ProUni passa a proporcionar o acesso aos cursos de maior prestígio social, representando um importante mecanismo de democratização das vagas para os alunos bolsistas. Por outro lado, a pesquisa destaca a falta de articulação entre o MEC e a IES na implementação do programa e a ausência de debate acadêmico sobre as ações afirmativas como pontos de fragilidade que caracterizam a adoção do ProUni na instituição.

Devido ao seu caráter filantrópico, a PUC-Rio possui longa tradição na adoção de políticas de inclusão de jovens carentes, fortalecidas a partir de 1994, quando o programa de bolsas de Ação Social desta universidade estabelece uma parceria com os Pré-Vestibulares Comunitários do Grande Rio. É nesse contexto de incorporação de estratos mais pobres ao corpo discente da universidade e consequente constatação de suas dificuldades materiais em prosseguir os estudos que, em março de 1997, surge o Fundo Emergencial de Solidariedade da PUC-Rio (Fesp) (Rodrigues, 2008). O Fesp atende bolsistas integrais com renda familiar de até um salário mínimo por pessoa e oferece auxílios em termos de alimentação, transporte, moradia e material didático. Como veremos, esta estrutura de apoio existente antes mesmo da criação do ProUni é fundamental também para os bolsistas de nossa amostra.

Outro tipo de auxílio começou a ser oferecido no segundo semestre de 2009, a partir da criação de um projeto fruto de uma parceria entre a PUCRio e a Secretaria Especial de Políticas de Promoção da Igualdade Racial (Seppir). O Protagonismo Universitário e Empoderamento Profissional (ProUniR) prevê duração de dois anos e realiza oficinas e atividades didático-pedagógicas não apenas para bolsistas ProUni, mas também para os demais bolsistas de Ação Social da universidade. Com o objetivo de melhorar o aproveitamento escolar e diminuir a evasão do aluno bolsista, especialmente pretos e pardos, o projeto promove oficinas de leitura e produção textual, distribuição de material didático, apoio psicopedagógico, visitas a diferentes espaços culturais, projetos de "gestão de carreira", entre outras atividades.

\section{Metodologia}

A pesquisa foi desenvolvida basicamente a partir de três conjuntos de informações. O primeiro, um questionário com perguntas abertas e fechadas, permitiu conhecer o perfil socioeconômico e cultural dos estudantes beneficiados pelo ProUni, além de fornecer conhecimento sobre diversos aspectos da vivência universitária: dificuldades vivenciadas, se o aluno já pensou em desistir do curso e por quais motivos, auxílios recebidos. Com o objetivo de estabelecer um contraponto entre o perfil socioeconômico dos bolsistas de nossa amostra e o corpo discente dos cursos escolhidos, utilizamos os dados do questionário socioeconômico do Exame Nacional de Desempenho dos Estudantes (Enade) de 2006. 
Além disso, foram realizadas entrevistas com alguns dos bolsistas que responderam ao questionário e forneceram seus contatos.

Quanto à escolha dos cursos, inicialmente a proposta da pesquisa era analisar a inserção universitária de bolsistas do ProUni matriculados em duas carreiras com graus distintos de prestígio social e que estivessem entre aqueles com o maior número de bolsistas na instituição. Visto que a resposta ao questionário era voluntária, e, também, o fornecimento de nome e telefone, uma opção dos bolsistas que aceitaram preenchê-lo, a intenção era obter uma quantidade significativa de respondentes identificados com nome e telefone para a seleção criteriosa daqueles que seriam entrevistados.

No entanto, verificou-se uma quantidade de bolsistas muito pequena nas áreas que tradicionalmente recebem estudantes de menor condição social - no caso da PUC-Rio, as Licenciaturas e Serviço Social -, sendo necessário repensar a escolha dos cursos. Optou-se, assim, por trabalhar com cursos de alto prestígio na hierarquia das carreiras, mas que se diferenciassem quanto ao nível sociocultural de seus alunos, o que poderia se revelar importante para o convívio com os colegas de sala de aula.

A partir desses critérios foram escolhidos os cursos de Psicologia e Direito, os quais apresentam algumas nuanças em relação a características individuais e familiares de seu corpo discente e possuem número elevado de bolsistas (Tabela 1). A decisão, por não incluir as carreiras que se dividem em várias habilitações, levou em consideração o fato de ser possível trocar de habilitação durante os primeiros períodos do curso, pois, em alguns casos, os bolsistas demoram a repassar essa informação à Vice-Reitoria Comunitária, o que poderia trazer problemas para a análise da permanência.

Como nem todos os bolsistas dos cursos amostrados responderam aos questionários, apresentou-se a possibilidade de incluir um terceiro curso na pesquisa. Tendo em vista que o final do semestre estava próximo, escolhemos o segundo curso com maior número de alunos do ProUni na PUC-Rio: Administração.

Tabela 1 - Características Socioculturais dos Alunos da PUC-Rio

\begin{tabular}{|l|c|c|c|}
\hline \multicolumn{1}{|c|}{ Variável } & Administração & Direito & Psicologia \\
\hline Alunos que se consideram de cor branca & $84,3 \%$ & $89,1 \%$ & $83,3 \%$ \\
\hline $\begin{array}{l}\text { Estudantes com faixa de renda mensal } \\
\text { familiar acima de R\$10.500,00 }\end{array}$ & $40,0 \%$ & $38,6 \%$ & $18,4 \%$ \\
\hline Pais com escolaridade de nível superior & $81,9 \%$ & $87,3 \%$ & $67,4 \%$ \\
\hline $\begin{array}{l}\text { Mães com escolaridade de nível superior } \\
\begin{array}{l}\text { Estudou todo o ensino médio em escola } \\
\text { privada }\end{array}\end{array}$ & $71,9 \%$ & $77,0 \%$ & $60,1 \%$ \\
\hline
\end{tabular}

Os questionários foram distribuídos pela Vice-Reitoria Comunitária da PUC-Rio no primeiro semestre de 2010. No total, 163 bolsistas responderam aos questionários, constituindo uma amostra de ingressantes de seis 
anos (2005-2010.1) (Tabela 2). A partir dos contatos fornecidos, foram selecionados cinco bolsistas de cada curso para realização das entrevistas individuais. Buscou-se garantir uma amostra que reunisse homens e mulheres, brancos e não brancos, estudantes dos períodos iniciais e finais. As entrevistas foram gravadas com autorização dos bolsistas e transcritas.

Tabela 2 - Amostra de Pesquisa

\begin{tabular}{|l|c|c|c|}
\multicolumn{1}{|c|}{ Curso } & $\begin{array}{c}\text { Total de Bolsistas ProUni } \\
\text { na PUC-Rio (2010.1) }\end{array}$ & $\begin{array}{c}\text { Amostra } \\
\text { da Pesquisa }\end{array}$ & Percentual \\
\hline Administração & 100 & 38 & $38,0 \%$ \\
\hline Direito & 119 & 85 & $71,0 \%$ \\
\hline Psicologia & 61 & 40 & $65,5 \%$ \\
\hline
\end{tabular}

\section{Caracterização socioeconômica dos bolsistas do ProUni}

Nesta primeira seção serão apresentados os resultados referentes ao perfil socioeconômico e cultural dos bolsistas ${ }^{3}$ de Administração, Direito e Psicologia da PUC-Rio. Ao longo do texto, apresentaremos alguns dados do questionário socioeconômico do Enade 2006 sobre as características individuais e familiares dos graduandos desses três cursos, de forma a melhor situar o caso dos bolsistas de nossa amostra. Ressalte-se que as percentagens serão utilizadas neste artigo apenas como um mecanismo para facilitar a comparação entre cursos e com os dados do Enade.

\section{Características individuais dos bolsistas: gênero, idade e cor}

Nas três carreiras analisadas em nossa pesquisa predominam bolsistas do ProUni do sexo feminino, com destaque para o curso de Psicologia, no qual 75,5\% ( $\mathrm{n}=30$ ) são mulheres; Administração, cuja proporção é de 63\% $(n=24)$ e Direito, onde esse valor é de $55 \%$ ( $n=$ 47). Neste sentido, o ProUni para os três cursos pesquisados na PUC-Rio favorece, sobretudo, a inclusão de pessoas do sexo feminino.

A maior parte dos bolsistas de nossa amostra, quase 80\%, concentra-se nas duas coortes de idade mais jovens (Tabela 3). Na primeira coorte, indicativa de uma trajetória escolar sem grandes atrasos e de ingresso na faculdade logo após o término do ensino médio, encontram-se $52 \%$ dos bolsistas de Direito, 42\% dos de Administração e 40\% dos de Psicologia. Nos cursos de Administração e Psicologia se encontra a maior proporção de bolsistas pertencentes à faixa etária ideal (até 24 anos) para o curso

${ }^{3}$ A partir daqui, o termo "bolsistas" será sempre utilizado em referência aos bolsistas do ProUn da PUC-Rio que responderam aos questionários de nossa pesquisa. Em caso de utilização para outros tipos de bolsas, o termo será especificado. superior, com índices de $92 \%$ e 80\%, respectivamente. Já o curso de Direito reúne o percentual mais expressivo de bolsistas com 25 anos ou mais. Com base nas entrevistas, é possível afirmar que, em muitos casos, o ProUni se mostrou como a alternativa mais viável para realização do projeto de transição imediata do ensino médio para a universidade. 
Tabela 3 - Coortes de Idade por Curso

\begin{tabular}{|c|c|c|c|c|c|}
\hline \multirow[b]{2}{*}{ Curso } & \multicolumn{4}{|c|}{ Coortes de Idade } & \multirow[b]{2}{*}{ Total } \\
\hline & $\begin{array}{c}\text { Até } 21 \\
\text { Anos }\end{array}$ & $\begin{array}{c}\text { Entre 22-24 } \\
\text { Anos }\end{array}$ & $\begin{array}{c}\text { Entre 25-30 } \\
\text { Anos }\end{array}$ & $\begin{array}{c}\text { Acima de } \\
30 \text { Anos }\end{array}$ & \\
\hline Psicologia & $\begin{array}{c}16 \\
40,0 \%\end{array}$ & $\begin{array}{c}16 \\
40,0 \%\end{array}$ & $\begin{array}{c}5 \\
12,5 \%\end{array}$ & $\begin{array}{c}3 \\
7,5 \%\end{array}$ & $\begin{array}{c}40 \\
100,0 \%\end{array}$ \\
\hline Administração & $\begin{array}{c}16 \\
42,1 \%\end{array}$ & $\begin{array}{c}19 \\
50,0 \%\end{array}$ & $\begin{array}{c}3 \\
7,9 \%\end{array}$ & $\begin{array}{c}0 \\
0,0 \%\end{array}$ & $\begin{array}{c}38 \\
100,0 \%\end{array}$ \\
\hline Direito & $\begin{array}{c}44 \\
51,8 \%\end{array}$ & $\begin{array}{c}19 \\
22,4 \%\end{array}$ & $\begin{array}{c}17 \\
20,0 \%\end{array}$ & $\begin{array}{c}5 \\
5,9 \%\end{array}$ & $\begin{array}{c}85 \\
100,0 \%\end{array}$ \\
\hline Total & $\begin{array}{c}76 \\
46,6 \%\end{array}$ & $\begin{array}{c}54 \\
33,1 \%\end{array}$ & $\begin{array}{c}25 \\
15,3 \%\end{array}$ & $\begin{array}{c}8 \\
4,9 \%\end{array}$ & $\begin{array}{c}163 \\
100,0 \%\end{array}$ \\
\hline
\end{tabular}

Em nossa amostra, os brancos representam 41,1\%, enquanto os pardos representam 39,9\% e os pretos, 16,6\%. Amarelos e indígenas somam apenas 2,5\% (Tabela 4). Psicologia é o curso que apresenta maior equilíbrio na distribuição das bolsas entre brancos (30\%), pretos (30\%) e pardos (40\%). Na Administração e no Direito predominam os bolsistas de cor branca, com uma importante presença de bolsistas autodeclarados pardos, 39,5\% e 40,0\% respectivamente, e reduzida participação de pretos, indígenas e amarelos.

Somando-se os percentuais para pretos e pardos, percebe-se que o número de bolsistas não brancos supera nos três cursos o número de bolsistas brancos. Estes números contrastam com o perfil racial que compõe o corpo discente desses cursos tanto na PUC-Rio, já expostos na seção dedicada à metodologia, como no Brasil, representado por cerca de 70\% de brancos nos três casos (Inep, 2006). A composição racial do grupo analisado mostra, portanto, que o sistema de cotas funcionou como um mecanismo positivo de inclusão para pretos e, principalmente, pardos nas três carreiras analisadas, com destaque para a presença significativa de bolsistas que se declaram pretos em Psicologia.

Tabela 4 - Cor dos Bolsistas por Curso

\begin{tabular}{|c|c|c|c|c|c|}
\hline Curso & Brancos & Pretos & Pardos & $\begin{array}{c}\text { Amarelos e } \\
\text { Indígenas }\end{array}$ & Total \\
\hline Psicologia & $\begin{array}{c}12 \\
30,0 \%\end{array}$ & $\begin{array}{c}12 \\
30,0 \%\end{array}$ & $\begin{array}{c}16 \\
40,0 \%\end{array}$ & $\begin{array}{c}0 \\
0 \%\end{array}$ & $\begin{array}{c}40 \\
100,0 \%\end{array}$ \\
\hline Administração & $\begin{array}{c}16 \\
42,1 \%\end{array}$ & $\begin{array}{c}5 \\
13,2 \%\end{array}$ & $\begin{array}{c}15 \\
39,5 \%\end{array}$ & $\begin{array}{c}2 \\
5,3 \%\end{array}$ & $\begin{array}{c}38 \\
100,0 \%\end{array}$ \\
\hline Direito & $\begin{array}{c}39 \\
45,9 \%\end{array}$ & $\begin{array}{c}10 \\
11,8 \%\end{array}$ & $\begin{array}{c}34 \\
40,0 \%\end{array}$ & $\begin{array}{c}2 \\
2,4 \%\end{array}$ & $\begin{array}{c}85 \\
100,0 \%\end{array}$ \\
\hline Total & $\begin{array}{c}67 \\
41,1 \%\end{array}$ & $\begin{array}{c}27 \\
16,6 \%\end{array}$ & $\begin{array}{c}65 \\
39,9 \%\end{array}$ & $\begin{array}{c}4 \\
2,5 \%\end{array}$ & $\begin{array}{c}163 \\
100,0 \%\end{array}$ \\
\hline
\end{tabular}




\section{Características familiares e de origem escolar}

A seguir analisa-se a escolaridade dos pais dos bolsistas, variável amplamente utilizada nos estudos sobre desigualdades educacionais e mobilidade social como uma medida do capital cultural familiar e da posição social da família. A partir da Tabela 5 constata-se um ambiente familiar cultural menos vantajoso para os bolsistas de Psicologia: 60\% dos pais de bolsistas desse curso têm escolaridade inferior ao ensino médio e 35\% não completaram nem a $5^{\mathrm{a}}$ série do ensino fundamental; além disso, apenas $22,5 \%$ dos pais dos bolsistas desse curso finalizaram o ensino médio. Em contraste, uma escolarização paterna mais prolongada caracteriza os beneficiados pelo ProUni na Administração e no Direito, cujos percentuais de pais com ensino médio completo são 44,7\% e 36,5\%, respectivamente. Também é no Direito que se encontra a maior percentagem $(15,3 \%)$ de pais que concluíram o ensino superior, seguido pela Administração (10,5\%) e, por último, pela Psicologia (5\%).

Tabela 5 - Escolaridade dos Pais dos Bolsistas

\begin{tabular}{|c|c|c|c|c|c|c|c|c|c|}
\hline Curso & $\begin{array}{c}\text { Nunca } \\
\text { Frequentou } \\
\text { a Escola }\end{array}$ & $\begin{array}{c}\text { Entre } 1^{\mathrm{a}} \mathrm{e} \\
4^{\mathrm{a}} \text { série do } \\
\text { Fundamental }\end{array}$ & $\begin{array}{c}\text { Entre } 5^{\mathrm{a}} \mathrm{e} \\
8^{\mathrm{a}} \text { série do } \\
\text { Fundamental }\end{array}$ & $\begin{array}{c}\text { Ensino } \\
\text { Médio } \\
\text { Incompleto }\end{array}$ & $\begin{array}{c}\text { Ensino } \\
\text { Médio } \\
\text { Completo }\end{array}$ & $\begin{array}{c}\text { Ensino } \\
\text { Superior } \\
\text { Incompleto }\end{array}$ & $\begin{array}{c}\text { Ensino } \\
\text { Superior } \\
\text { Completo }\end{array}$ & $\begin{array}{c}\text { Não } \\
\text { Respondeu }\end{array}$ & Total \\
\hline Administração & $\begin{array}{c}0 \\
0,0 \%\end{array}$ & $\begin{array}{c}5 \\
13,2 \%\end{array}$ & $\begin{array}{c}8 \\
21,1 \%\end{array}$ & $\begin{array}{c}0 \\
0,0 \%\end{array}$ & $\begin{array}{c}17 \\
44,7 \%\end{array}$ & $\begin{array}{c}1 \\
2,6 \%\end{array}$ & $\begin{array}{c}4 \\
10,5 \%\end{array}$ & $\begin{array}{c}3 \\
7,9 \%\end{array}$ & $\begin{array}{c}38 \\
100,0 \%\end{array}$ \\
\hline Direito & $\begin{array}{c}1 \\
1,2 \%\end{array}$ & $\begin{array}{c}10 \\
11,8 \%\end{array}$ & $\begin{array}{c}10 \\
11,8 \%\end{array}$ & $\begin{array}{c}7 \\
8,2 \%\end{array}$ & $\begin{array}{c}31 \\
36,5 \%\end{array}$ & $\begin{array}{c}5 \\
5,9 \%\end{array}$ & $\begin{array}{c}13 \\
15,3 \%\end{array}$ & $\begin{array}{c}8 \\
9,4 \%\end{array}$ & $\begin{array}{c}85 \\
100,0 \%\end{array}$ \\
\hline Psicologia & $\begin{array}{c}1 \\
2,5 \%\end{array}$ & $\begin{array}{c}13 \\
32,5 \%\end{array}$ & $\begin{array}{c}9 \\
22,5 \%\end{array}$ & $\begin{array}{c}1 \\
2,5 \%\end{array}$ & $\begin{array}{c}9 \\
22,5 \%\end{array}$ & $\begin{array}{c}5 \\
12,5 \%\end{array}$ & $\begin{array}{c}2 \\
5,0 \%\end{array}$ & $\begin{array}{c}0 \\
0,0 \%\end{array}$ & $\begin{array}{c}40 \\
100,0 \%\end{array}$ \\
\hline Total & $\begin{array}{c}2 \\
1,2 \%\end{array}$ & $\begin{array}{c}28 \\
17,2 \%\end{array}$ & $\begin{array}{c}27 \\
16,6 \%\end{array}$ & $\begin{array}{c}8 \\
4,9 \%\end{array}$ & $\begin{array}{c}57 \\
35,0 \%\end{array}$ & $\begin{array}{c}11 \\
6,7 \%\end{array}$ & $\begin{array}{c}19 \\
11,7 \%\end{array}$ & $\begin{array}{c}11 \\
6,7 \%\end{array}$ & $\begin{array}{c}163 \\
100,0 \%\end{array}$ \\
\hline
\end{tabular}

Verifica-se, através do que foi acima observado, que a variável de capital cultural paterno dos bolsistas ProUni se afasta bastante dos valores para o corpo discente geral da PUC-Rio, cujo percentual é de 79\% dos pais com instrução superior (Inep, 2006). A partir desses dados, constata-se, portanto, que os bolsistas de nossa amostra convivem no ambiente universitário com estudantes de tradição sociocultural bastante diferente, para os quais o diploma de nível superior já integra o patrimônio escolar familiar.

Quanto à renda, 51,5\% dos bolsistas de nossa pesquisa declararam uma renda familiar mensal de $\mathrm{R} \$ 750$ até $\mathrm{R} \$ 1.500$ reais, sendo que, na Psicologia, 47,5\% se situam nesta faixa de renda, na Administração, $47,4 \%$ e no Direito, 55,3\% (Tabela 6). Os dados corroboram com o que foi verificado para a escolaridade paterna, ou seja, os bolsistas de Direito, em geral, apresentam uma condição econômica mais favorável: apenas $8,3 \%$ dos estudantes desse curso pertencem à faixa de renda inferior, em comparação a um percentual de 21,1\% em Administração e 22,5\% em Psicologia, que possui menor número de bolsistas nas duas faixas de renda superiores. Confirma-se, assim, a posição intermediária na escala 
socioeconômica dos bolsistas de Administração e o que foi afirmado sobre a situação social ligeiramente inferior dos bolsistas de Psicologia em comparação aos outros dois cursos.

Tabela 6 - Renda Familiar Mensal segundo o Curso

\begin{tabular}{|c|c|c|c|c|c|c|}
\hline Curso & $\begin{array}{c}\text { Até } \\
\text { R\$ } 750\end{array}$ & $\begin{array}{c}\text { Entre } \\
\mathbf{R} \$ 750 \mathrm{e} \\
\mathbf{R} \$ 1.500\end{array}$ & $\begin{array}{c}\text { Entre } \\
\text { R\$ } 1.500 \mathrm{e} \\
\mathrm{R} \$ 2.500\end{array}$ & $\begin{array}{c}\text { Entre } \\
\mathbf{R} \$ 2.500 \mathrm{e} \\
\mathbf{R} \$ 5.000\end{array}$ & $\begin{array}{c}\text { Não } \\
\text { Respondeu }\end{array}$ & Total \\
\hline Psicologia & $\begin{array}{c}9 \\
22,5 \%\end{array}$ & $\begin{array}{c}19 \\
47,5 \%\end{array}$ & $\begin{array}{c}10 \\
25,0 \%\end{array}$ & $\begin{array}{c}1 \\
2,5 \%\end{array}$ & $\begin{array}{c}1 \\
2,5 \%\end{array}$ & $\begin{array}{c}40 \\
100,0 \%\end{array}$ \\
\hline Administração & $\begin{array}{c}8 \\
21,1 \%\end{array}$ & $\begin{array}{c}18 \\
47,4 \%\end{array}$ & $\begin{array}{c}12 \\
31,6 \%\end{array}$ & $\begin{array}{c}0 \\
0,0 \%\end{array}$ & $\begin{array}{c}0 \\
0,0 \%\end{array}$ & $\begin{array}{c}38 \\
100,0 \%\end{array}$ \\
\hline Direito & $\begin{array}{c}7 \\
8,3 \%\end{array}$ & $\begin{array}{c}47 \\
55,3 \%\end{array}$ & $\begin{array}{c}23 \\
27,1 \%\end{array}$ & $\begin{array}{c}5 \\
5,9 \%\end{array}$ & $\begin{array}{c}3 \\
3,5 \%\end{array}$ & $\begin{array}{c}85 \\
100,0 \%\end{array}$ \\
\hline Total & $\begin{array}{c}24 \\
14,8 \%\end{array}$ & $\begin{array}{c}84 \\
51,5 \%\end{array}$ & $\begin{array}{c}45 \\
27,6 \%\end{array}$ & $\begin{array}{c}6 \\
3,7 \%\end{array}$ & $\begin{array}{c}4 \\
2,5 \%\end{array}$ & $\begin{array}{c}163 \\
100,0 \%\end{array}$ \\
\hline
\end{tabular}

Em comparação à totalidade de estudantes de Administração e Direito da PUC-Rio, os bolsistas ProUni destes dois cursos integram um estrato econômico bem menos favorecido; de fato, nesta instituição, em ambos os cursos, praticamente $40 \%$ do corpo discente provem de famílias cuja renda mensal é superior a $\mathrm{R} \$ 10.500,00$, e, mesmo na Psicologia, onde há uma distribuição mais equitativa dos estudantes entre as diversas faixas de renda, ${ }^{4}$ só as duas faixas mais altas (de $\mathrm{R} \$ 7.001,00$ até $\mathrm{R} \$ 10.500,00$ e acima de $R \$ 10.500,00$ ) agregam 33\% do total de estudantes deste curso (Inep, 2006).

Sobre a participação dos alunos bolsistas na renda domiciliar, 50\% dos bolsistas de Administração e Direito não possuem nenhuma fonte de renda, tendo seus gastos financiados pelas famílias. ${ }^{5}$ Psicologia, único curso da amostra com carga horária integral, apresenta o maior percentual (55\%) de estudantes que declararam não possuir rendimentos e o maior percentual de bolsistas que, apesar de trabalharem, precisam de algum tipo de ajuda financeira para se manterem. Nota-se também uma importante parcela de bolsistas de Administração que afirmaram dividir o sustento da casa $(15,8 \%)$ ou custearem seus gastos pessoais $(13,2 \%)$, sugerindo que a estrutura familiar dos estudantes deste curso requer maiores responsabilidades econômicas no domicílio.

Esses dados, juntamente com a informação sobre a contribuição desses jovens para a renda familiar (obtida através do somatório das percentagens das alternativas "me sustento e ajudo em casa", "divido o sustento da casa" e "principal responsável pelo sustento da casa"), permitem afirmar que são os bolsistas de Administração e Direito que mais possuem algum tipo de responsabilidade econômica no domicílio, enquanto os bolsistas de Psicologia, justamente o grupo com indicadores

\footnotetext{
${ }^{4}$ O Enade 2006 utilizou sete faixas de renda, a saber: até $\mathrm{R} \$ 1.050,00 ;$ de $\mathrm{R} \$ 1.051$ até $\mathrm{R} \$ 1.750,00 ;$ de $\mathrm{R} \$ 1.751,00$ até R\$ 3.050,00; de R\$3.051,00 até $\mathrm{R} \$ 5.250,00 ;$ de $\mathrm{R} \$ 5.251,00$ até $\mathrm{R} \$ 7.000,00$; de $\mathrm{R} \$ 7.001,00$ até R\$10.500,00 e mais de $\mathrm{R} \$ 10.500,00$.

${ }^{5}$ Nesta questão foram consideradas outras rendas além das advindas com o trabalho, por exemplo, a remuneração por estágios ou bolsas de pesquisas.
} 
socioculturais mais baixos, dependem mais de suas famílias para se sustentarem. Os dados podem ser visualizados na Tabela 7.

Tabela 7 - Responsabilidade Econômica dos Bolsistas no Domicílio

\begin{tabular}{|c|c|c|c|c|c|c|c|c|}
\hline Curso & $\begin{array}{l}\text { Não tenho } \\
\text { rendimentos }\end{array}$ & $\begin{array}{c}\text { Trabalho, } \\
\text { mas } \\
\text { recebo } \\
\text { ajuda } \\
\text { financeira }\end{array}$ & $\begin{array}{c}\text { Financeiramente } \\
\text { independente }\end{array}$ & $\begin{array}{c}\text { Me } \\
\text { sustento } \\
\text { e ajudo } \\
\text { em casa }\end{array}$ & $\begin{array}{c}\text { Divido o } \\
\text { sustento } \\
\text { da casa }\end{array}$ & $\begin{array}{c}\text { Principal } \\
\text { responsável } \\
\text { pelo } \\
\text { sustento } \\
\text { da casa }\end{array}$ & $\begin{array}{c}\text { Outra } \\
\text { situação }\end{array}$ & Total \\
\hline Psicologia & $\begin{array}{c}22 \\
55,0 \%\end{array}$ & $\begin{array}{c}4 \\
10,0 \%\end{array}$ & $\begin{array}{c}4 \\
10,0 \%\end{array}$ & $\begin{array}{c}6 \\
15,0 \%\end{array}$ & $\begin{array}{c}0 \\
0,0 \%\end{array}$ & $\begin{array}{c}2 \\
5,0 \%\end{array}$ & $\begin{array}{c}2 \\
5,0 \%\end{array}$ & $\begin{array}{c}40 \\
100,0 \%\end{array}$ \\
\hline Administração & $\begin{array}{c}19 \\
50,0 \%\end{array}$ & $\begin{array}{c}2 \\
5,3 \%\end{array}$ & $\begin{array}{c}5 \\
13,2 \%\end{array}$ & $\begin{array}{c}4 \\
10,5 \%\end{array}$ & $\begin{array}{c}6 \\
15,8 \%\end{array}$ & $\begin{array}{c}1 \\
2,6 \%\end{array}$ & $\begin{array}{c}1 \\
2,6 \%\end{array}$ & $\begin{array}{c}38 \\
100,0 \%\end{array}$ \\
\hline Direito & $\begin{array}{c}42 \\
50,0 \%\end{array}$ & $\begin{array}{c}6 \\
7,1 \%\end{array}$ & $\begin{array}{c}7 \\
8,3 \%\end{array}$ & $\begin{array}{c}10 \\
11,9 \%\end{array}$ & $\begin{array}{c}11 \\
13,1 \%\end{array}$ & $\begin{array}{c}4 \\
4,8 \%\end{array}$ & $\begin{array}{c}4 \\
4,8 \%\end{array}$ & $\begin{array}{c}84 \\
100,0 \%\end{array}$ \\
\hline Total & $\begin{array}{c}83 \\
51,2 \%\end{array}$ & $\begin{array}{c}12 \\
7,4 \%\end{array}$ & $\begin{array}{c}16 \\
9,9 \%\end{array}$ & $\begin{array}{c}20 \\
12,3 \%\end{array}$ & $\begin{array}{c}17 \\
10,5 \%\end{array}$ & $\begin{array}{c}7 \\
4,3 \%\end{array}$ & $\begin{array}{c}7 \\
4,3 \%\end{array}$ & $\begin{array}{c}162 \\
100,0 \%\end{array}$ \\
\hline
\end{tabular}

A próxima variável de análise é "origem escolar dos bolsistas" (Tabela 8). Na rede pública estadual estudaram $56,2 \%$ dos bolsistas de nossa amostra, principalmente os dos cursos de Psicologia (72,5\%) e Direito (54,1\%). Entre os bolsistas de Administração, esse percentual é um pouco menor, 43,2\%. A parcela de alunos provenientes dos colégios federais é de 32,4\% na Administração, 29,4\% no Direito e 22,5\% na Psicologia. Administração e Direito também apresentam uma percentagem mais expressiva de bolsistas provenientes de colégios privados, 18,4\% e 15,3\%, respectivamente, se compararmos com a Psicologia (2,5\%), e a rede municipal representa apenas $2,5 \%$ ou quatro casos do total de escolas.

\section{Tabela 8 - Rede Administrativa das Escolas de Ensino Médio segundo o Curso}

\begin{tabular}{|c|c|c|c|c|c|}
\hline \multirow{2}{*}{ Curso } & \multicolumn{4}{|c|}{ Rede Administrativa } & \multirow{2}{*}{ Total } \\
\hline & Municipal & Estadual & Federal & Particular & \\
\hline Psicologia & $\begin{array}{c}1 \\
2,5 \%\end{array}$ & $\begin{array}{c}29 \\
72,5 \%\end{array}$ & $\begin{array}{c}9 \\
22,5 \%\end{array}$ & $\begin{array}{c}1 \\
2,5 \%\end{array}$ & $\begin{array}{c}40 \\
100,0 \%\end{array}$ \\
\hline Administração & $\begin{array}{c}2 \\
5,4 \%\end{array}$ & $\begin{array}{c}16 \\
43,2 \%\end{array}$ & $\begin{array}{c}12 \\
32,4 \%\end{array}$ & $\begin{array}{c}7 \\
18,9 \%\end{array}$ & $\begin{array}{c}37 \\
100,0 \%\end{array}$ \\
\hline Direito & $\begin{array}{c}1 \\
1,2 \%\end{array}$ & $\begin{array}{c}46 \\
54,1 \%\end{array}$ & $\begin{array}{c}25 \\
29,4 \%\end{array}$ & $\begin{array}{c}13 \\
15,3 \%\end{array}$ & $\begin{array}{c}85 \\
100,0 \%\end{array}$ \\
\hline Total & $\begin{array}{c}4 \\
2,5 \%\end{array}$ & $\begin{array}{c}91 \\
56,2 \%\end{array}$ & $\begin{array}{c}46 \\
28,4 \%\end{array}$ & $\begin{array}{c}21 \\
13,0 \%\end{array}$ & $\begin{array}{c}162 \\
100,0 \%\end{array}$ \\
\hline
\end{tabular}

Em termos do tipo de escola frequentada no ensino médio, este também é um público muito diferente daquele que a PUC-Rio seleciona em seus vestibulares. Segundo o Enade 2006, nesta IES a frequência de 
alunos provenientes de escolas privadas na Administração e no Direito era de 90\%, enquanto para Psicologia esse percentual era de $78,4 \%$. O ProUni, portanto, tem incrementado as chances de os estudantes da rede pública - especialmente a estadual - ingressarem na PUC-Rio.

\section{Inserção universitária}

Com exceção dos estudantes de Psicologia, que têm aulas em período integral, os demais bolsistas frequentam em sua maioria as aulas no turno diurno (61\% ou 52 alunos de Direito e 68\% ou 25 alunos de Administração). Destaque-se que, na PUC-Rio, tanto em Administração como no Direito, uma maior quantidade de bolsas do ProUni é ofertada para o período da manhã.

Quanto às atividades extracurriculares, no curso de Psicologia, 60\% dos bolsistas já participaram ou participam de pelo menos uma delas; neste caso, o destaque é para a participação em equipes de pesquisas e de estágios remunerados. No que diz respeito à proporção de estudantes que já estiveram em estágios remunerados, ela é mais expressiva nos outros dois cursos de nossa amostra: 28,9\% na Administração e 36,5\% no Direito. Um aspecto positivo é a boa inserção dos alunos nessas atividades ao longo dos cursos: considerando os bolsistas dos últimos três períodos, todos participaram de ao menos uma delas, exceção feita a um bolsista do curso de Psicologia.

Tabela 9 - Atividade Exercida Predominantemente durante a Graduação

\begin{tabular}{|c|c|c|c|c|c|c|c|}
\hline Curso & Extensão & Monitoria & $\begin{array}{l}\text { Equipe } \\
\text { de } \\
\text { Pesquisa }\end{array}$ & $\begin{array}{c}\text { Estágio } \\
\text { Remunerado }\end{array}$ & $\begin{array}{l}\text { Estágio não } \\
\text { Remunerado }\end{array}$ & $\begin{array}{c}\text { Nunca } \\
\text { participei } \\
\text { dessas } \\
\text { atividades }\end{array}$ & Total \\
\hline Psicologia & $\begin{array}{c}0 \\
0,0 \%\end{array}$ & $\begin{array}{c}1 \\
2,5 \%\end{array}$ & $\begin{array}{c}9 \\
22,5 \%\end{array}$ & $\begin{array}{c}9 \\
22,5 \%\end{array}$ & $\begin{array}{c}5 \\
12,5 \%\end{array}$ & $\begin{array}{c}16 \\
40,0 \%\end{array}$ & $\begin{array}{c}40 \\
100,0 \%\end{array}$ \\
\hline Administração & $\begin{array}{c}0 \\
0,0 \%\end{array}$ & $\begin{array}{c}2 \\
5,3 \%\end{array}$ & $\begin{array}{c}2 \\
5,3 \%\end{array}$ & $\begin{array}{c}11 \\
28,9 \%\end{array}$ & $\begin{array}{c}1 \\
2,6 \%\end{array}$ & $\begin{array}{c}22 \\
57,9 \%\end{array}$ & $\begin{array}{c}38 \\
100,0 \%\end{array}$ \\
\hline Direito & $\begin{array}{c}1 \\
1,2 \%\end{array}$ & $\begin{array}{c}1 \\
1,2 \%\end{array}$ & $\begin{array}{c}6 \\
7,1 \%\end{array}$ & $\begin{array}{c}31 \\
36,5 \%\end{array}$ & $\begin{array}{c}4 \\
4,7 \%\end{array}$ & $\begin{array}{c}42 \\
49,4 \%\end{array}$ & $\begin{array}{c}85 \\
100,0 \%\end{array}$ \\
\hline Total & $\begin{array}{c}1 \\
0,6 \%\end{array}$ & $\begin{array}{c}4 \\
2,5 \%\end{array}$ & $\begin{array}{c}17 \\
10,4 \%\end{array}$ & $\begin{array}{c}51 \\
31,3 \%\end{array}$ & $\begin{array}{c}10 \\
6,1 \%\end{array}$ & $\begin{array}{c}80 \\
49,1 \%\end{array}$ & $\begin{array}{c}163 \\
100,0 \%\end{array}$ \\
\hline
\end{tabular}

Em relação aos auxílios recebidos pelos estudantes de nossa pesquisa, no primeiro semestre de 2010, 47,5\% ( $\mathrm{n}=19)$ dos bolsistas de Psicologia, $60 \%(n=23)$ de Administração e 56,4\% ( $n=48)$ dos bolsistas de Direito não recebiam nenhum tipo de auxílio financeiro para sua manutenção na universidade. Estão incluídos neste grupo 32 alunos (9 na Psicologia, 9 na Administração e 14 no Direito), que, por estarem no primeiro período, ainda não haviam tido sua condição econômica avaliada pelo Fesp. 
A distribuição dos recursos mostra que, na Psicologia, metade dos alunos recebe auxílio para o transporte, refeição durante estadia na PUCRio e material didático. Esses índices são menores para os outros dois cursos, especialmente no que se refere ao material didático. Apenas 5,1\%, ou oito bolsistas de nossa amostra, recebiam uma ajuda financeira, cedida em casos extremos, geralmente aos bolsistas vindos de outros Estados ou de cidades do interior do Rio de Janeiro, para morarem próximos à PUC-Rio. A alternativa "outro auxílio" refere-se a cópias e impressões extras de material e a dois estudantes de Direito que recebiam apoio financeiro/material de entidades não vinculadas à PUC-Rio. Esses dados estão expostos na Tabela 10.

Tabela 10 - Distribuição dos Auxílios por Curso

\begin{tabular}{|c|c|c|c|c|c|}
\hline Curso & $\begin{array}{c}\text { Auxílio } \\
\text { Moradia }\end{array}$ & $\begin{array}{c}\text { Auxílio } \\
\text { Transporte }\end{array}$ & $\begin{array}{c}\text { Auxílio } \\
\text { Refeição }\end{array}$ & $\begin{array}{c}\text { Auxílio } \\
\text { Material } \\
\text { Didático }\end{array}$ & $\begin{array}{c}\text { Outro } \\
\text { Auxílio }\end{array}$ \\
\hline Psicologia & 3 & 20 & 19 & 20 & 4 \\
\hline \multirow{2}{*}{ Administração } & $7,7 \%$ & $51,3 \%$ & $48,7 \%$ & $51,3 \%$ & $10,3 \%$ \\
\hline \multirow{2}{*}{ Direito } & 1 & 14 & 13 & 9 & 2 \\
\hline \multirow{2}{*}{ Total } & $2,8 \%$ & $38,9 \%$ & $36,1 \%$ & $25,0 \%$ & $5,6 \%$ \\
\hline & 4 & 33 & 32 & 11 & 4 \\
\hline & $\mathbf{4 , 8}, \mathbf{8} \%$ & $39,8 \%$ & $38,6 \%$ & $13,3 \%$ & $4,8 \%$ \\
\hline
\end{tabular}

Com relação às dificuldades para a permanência no ensino superior, apenas 10\% ( $\mathrm{n}=4)$ dos bolsistas de Psicologia, 18\% $(\mathrm{n}=7)$ do curso de Administração e $12 \%(n=10)$ de Direito declararam uma inserção na instituição sem maiores problemas. Na verdade, para muitos bolsistas, o primeiro período da graduação é um dos mais difíceis de ser "vencido", porque geralmente, nesta etapa, o aluno não tem acesso aos auxílios do Fesp.

Para a pergunta sobre situações adversas experimentadas ${ }^{6}$ (Tabela 11), as duas alternativas que tiveram maior percentual de escolha em todos os cursos da amostra foram "dificuldades de custear materiais de estudo, alimentação e transporte" e "dedicação do tempo adequado aos estudos". Observa-se que foram os bolsistas de Psicologia os que mais enfrentaram ou enfrentam problemas com os gastos advindos da

${ }^{6}$ Eram apresentadas cinco alternativas com possíveis situações adversas experimentadas, e o aluno podia marcar quantas alternativas fossem necessárias. 7 Se reunirmos os percentuais referentes a algumas das áreas mais afastadas da Zona Sul Zona Norte, Zona Oeste, Baixada Fluminense e outros municípios do Estado do Rio -, verifica-se que $60 \%$ dos bolsistas vivem em regiões afastadas do campus da PUC-Rio. vida universitária (77,5\% ou 31 bolsistas); o que na verdade reflete a condição socioeconômica inferior deste grupo é o fato de mais da metade não possuir qualquer fonte de renda, seja advinda de trabalho, seja de estágios.

Para aqueles que não são contemplados com a ajuda financeira/ material da instituição, a situação é especialmente complicada. Além de residirem em regiões afastadas da Zona Sul ${ }^{7}$ e, logo, percorrerem grandes distâncias e/ou enfrentarem trânsito para chegar à PUC-Rio, esses estudantes começam a estagiar ou trabalhar desde os períodos 
iniciais da faculdade para cobrirem os gastos do dia a dia na universidade e, às vezes, até mesmo ajudarem nas despesas familiares. Nessas situações, tanto o tempo despendido no trajeto percorrido - um dos elementos mais "desmotivadores", segundo os bolsistas - como a rotina de estágio ou de trabalho reduzem as horas livres para uma dedicação plena aos estudos ou mesmo para as atividades de lazer, conforme foi relatado no questionário por um bolsista de Administração do $5^{\circ}$ período: "Passo aproximadamente duas horas no trajeto Caxias-Gávea. Cansado. Meu trabalho me toma muito tempo, e ainda preciso estudar. Não tenho tempo para mais nada."

Um dado positivo é oferecido pelas respostas sobre o "acompanhamento e compreensão de disciplinas": apenas 7,5\% $(n=3)$ na Psicologia e $10,7 \%(n=9)$ no Direito afirmaram ter alguma dificuldade neste aspecto. Os bolsistas de Administração apresentaram o maior percentual de dificuldades relacionado aos conteúdos vistos em sala. As dificuldades relatadas pelos bolsistas deste curso referem-se principalmente às disciplinas que exigem conhecimentos de matemática; e, ainda que nos questionários, na maioria das vezes, a "falta de tempo" ou o "morar longe" sejam apontados como a explicação para as dificuldades acadêmicas, ficou mais claro, através das entrevistas, o papel de uma base escolar deficiente nos níveis anteriores de escolarização para as dificuldades enfrentadas por alguns bolsistas.

Tendo em vista que os bolsistas de Administração apresentaram mais dificuldades para a compreensão das disciplinas, entende-se o porquê de este grupo ser o que mais participa de atividades de reforço (15 bolsistas), que em sua quase totalidade refere-se às atividades de monitoria realizadas no âmbito do próprio departamento, onde são revisados os conteúdos vistos em sala de aula. Apenas quatro bolsistas de Psicologia e três de Direito afirmaram participar das atividades de reforço escolar, e, nestes casos, declararam frequentar as oficinas do ProUnir.

É importante ressaltar que os entrevistados demonstraram desconhecer algumas exigências estabelecidas pelo ProUni. Assim, a alternativa que se referia ao "aproveitamento e frequência" exigidos pelo Programa foi em alguns casos interpretada como dificuldades de manter um Coeficiente de Rendimento alto, enquanto na verdade refere-se à necessidade de aprovação em 75\% das disciplinas cursadas em cada período letivo. É possível também que a própria formulação da questão, ao usar o termo adotado pelo MEC ("aproveitamento"), tenha induzido ao erro. De qualquer forma, sinaliza-se que seis bolsistas de Psicologia, 13 de Administração e 19 de Direito consideram seu rendimento acadêmico baixo.

A inserção desses bolsistas na instituição estudada, no entanto, não significa apenas vencer dificuldades materiais. Como já apontado em artigo sobre os bolsistas de Ação Social da PUC-Rio (Dauster, 2004), as diferenças sociais e culturais entre bolsistas e não bolsistas traduzem-se como mais uma barreira a ser superada. 
Tabela 11 - Dificuldades Vivenciadas no Ensino Superior

\begin{tabular}{|c|c|c|c|c|c|}
\hline Curso & $\begin{array}{c}\text { Manter } \\
\text { aproveitamento } \\
\text { exigido pelo } \\
\text { ProUni }\end{array}$ & $\begin{array}{c}\text { Dedicar } \\
\text { tempo } \\
\text { adequado } \\
\text { aos } \\
\text { estudos }\end{array}$ & $\begin{array}{c}\text { Custear } \\
\text { materiais, } \\
\text { transporte, } \\
\text { alimentação }\end{array}$ & $\begin{array}{l}\text { Acompanhamento } \\
\text { e compreensão de } \\
\text { disciplinas }\end{array}$ & $\begin{array}{c}\text { Relacionamento } \\
\text { com a turma/ } \\
\text { colegas }\end{array}$ \\
\hline Psicologia & $\begin{array}{c}6 \\
15 \%\end{array}$ & $\begin{array}{c}16 \\
40,0 \%\end{array}$ & $\begin{array}{c}31 \\
77,5 \%\end{array}$ & $\begin{array}{c}3 \\
7,5 \%\end{array}$ & $\begin{array}{c}9 \\
22,5 \%\end{array}$ \\
\hline Administração & $\begin{array}{c}13 \\
34,2 \%\end{array}$ & $\begin{array}{c}25 \\
65,8 \%\end{array}$ & $\begin{array}{c}26 \\
68,4 \%\end{array}$ & $\begin{array}{c}14 \\
36,8 \%\end{array}$ & $\begin{array}{c}5 \\
13,2 \%\end{array}$ \\
\hline Direito & $\begin{array}{c}19 \\
22,6 \%\end{array}$ & $\begin{array}{c}49 \\
58,3 \%\end{array}$ & $\begin{array}{c}56 \\
66,7 \%\end{array}$ & $\begin{array}{c}9 \\
10,7 \%\end{array}$ & $\begin{array}{c}19 \\
22,6 \%\end{array}$ \\
\hline Total & $\begin{array}{c}38 \\
23,5 \%\end{array}$ & $\begin{array}{c}90 \\
55,6 \%\end{array}$ & $\begin{array}{c}113 \\
69,8 \%\end{array}$ & $\begin{array}{c}26 \\
16,0 \%\end{array}$ & $\begin{array}{c}33 \\
20,4 \%\end{array}$ \\
\hline
\end{tabular}

Ainda tomando a Tabela 11 como referência, percebe-se que os cursos de Direito e Psicologia apresentam as maiores percentagens de bolsistas que afirmaram ter passado por algum tipo de dificuldade de relacionamento com a turma ou com os colegas. O cruzamento da variável "dificuldade de relacionamento" com a variável "cor do estudante" indica uma tendência dos bolsistas autodeclarados pardos a sentirem maior dificuldade de interação em comparação aos outros grupos de cores. Com efeito, no grupo de pardos, $26,6 \%(n=17)$ disseram possuir alguma dificuldade de relacionamento no ambiente universitário, sendo esta proporção de 16,4\% ( $\mathrm{n}=11)$ entre os bolsistas brancos e 14,8\% $(n=4)$ entre os pretos. Também os bolsistas com origem familiar mais baixa e os provenientes de colégios públicos estaduais apresentaram maior percentual de estudantes que marcaram esta alternativa.

Esses resultados, associados aos resultados das entrevistas, indicam que as dificuldades de relacionamento são percebidas mais em termos sociais do que raciais. Também não há uma percepção generalizada de que esses problemas de convivência sejam fruto de práticas de preconceito racial ou social por parte dos alunos pagantes, ainda que tenham sido relatadas algumas situações percebidas enquanto tais e uma entrevistada tenha afirmado sofrer preconceito social. A visão abaixo resume a perspectiva da maioria dos bolsistas entrevistados:

[...] a gente chega aqui e é um ambiente hostil. Porque eu acho que se não fosse essas pessoas da sala [outros bolsistas], que fomos falando da mesma realidade, eu não sei como seria. Não é que role preconceito, não é isso, ao menos comigo nunca teve, mas é realmente a diferença social. Eu não vejo acontecer preconceito. O que eu vejo, às vezes, é ( $\operatorname{sic}$ ) as pessoas não terem noção que tem gente que não é da mesma classe social deles aqui. (Bolsista de Psicologia, $9^{\circ}$ período).

Assim, as formas de interação entre bolsistas e não bolsistas são mais superficiais e ocasionais: fala-se com "todo mundo" sem distinção, mas os "amigos" são outros bolsistas. Para tanto, não é preciso que a 
condição de bolsista seja declarada desde o primeiro momento, já que o reconhecimento e a identificação com o outro ocorre através das formas mais sutis do dia a dia, seja pela roupa ou calçado usado, pelos assuntos das conversas, seja pelo lugar que se ocupa na sala de aula. De maneira semelhante, a referência ao grupo de bolsistas é feita através de princípios de classificação que valorizam o "amadurecimento", o "esforço" e a "dedicação" de quem "está ali para o tudo ou nada". Neste sentido, cria-se um distanciamento entre bolsistas e não bolsistas:

[...] Com relação à convivência em sala de aula é bem aquela turminha de colégio, sabe? Um grupo aqui, outro grupo ali, um grupo de bolsistas aqui, o pessoal que paga a faculdade ali, o pessoal que estuda 'tá' ali. Da convivência acho que fica um pouco... Não sei se até por questão do próprio bolsista acabar se distanciando mesmo, é uma realidade diferente, pelo menos a minha. [...] Não sei, pode ser que alguns [bolsistas] procurem se afastar um pouco. Você tem uma realidade diferente da minha, não tem compatibilidade, você faz isso sem ter... Não faz conscientemente, faz inconscientemente. Neste sentido, às vezes eu acho que até eu me afasto mesmo. Eu busco mais as pessoas que eu vejo que têm a mesma realidade que eu, não sei. Converso com o pessoal todo, mas eu vejo que não tenho uma proximidade tão grande como eu tenho com os bolsistas. (Bolsista de Direito, $7^{\circ}$ período).

Outra medida de como se processa a inserção universitária nestes casos pode ser avaliada pela Tabela 12. Verifica-se que uma grande quantidade de bolsistas, principalmente os graduandos dos dois cursos com medidas de capital econômico e cultural mais baixas - Psicologia e Administração -, afirmaram que já pensaram em desistir do curso. Nestas duas carreiras, os custos advindos com a vida universitária e o/a cansaço/desmotivação pelo tempo gasto no trajeto de casa à universidade estão entre os motivos mais recorrentes citados nos questionários para explicar uma possível desistência. Uma terceira justificativa citada pelos bolsistas de Psicologia foram as dúvidas com relação à escolha do curso, e, na Administração, as dificuldades de desempenho acadêmico. Já no Direito, além das questões de ordem financeira e incertezas quanto à escolha da carreira, a necessidade de conciliar estudo com trabalho ou outras atividades (por exemplo, afazeres domésticos) também está entre os principais entraves para a permanência.

Tabela 12 - Desistência

\begin{tabular}{|l|c|c|c|}
\hline \multirow{2}{*}{ Curso } & \multicolumn{2}{|c|}{ Já pensou em desistir do curso? } & \multirow{2}{*}{ Total } \\
\cline { 2 - 3 } & Não & Sim & \\
\hline \multirow{2}{*}{ Psicologia } & 17 & 23 & 40 \\
& $42,5 \%$ & $57,5 \%$ & $100,0 \%$ \\
\hline \multirow{2}{*}{ Administração } & 23 & 15 & 38 \\
\hline \multirow{2}{*}{ Direito } & $60,5 \%$ & $39,5 \%$ & $100,0 \%$ \\
\hline \multirow{2}{*}{ Total } & 55 & 30 & 85 \\
& $64,7 \%$ & $35,3 \%$ & $100,0 \%$ \\
\hline
\end{tabular}


Por fim, a última dimensão de análise que será tratada aqui investiga quais os principais atores que ofereceram suporte aos bolsistas diante das dificuldades encontradas. ${ }^{8}$ Uma primeira constatação é o papel central desempenhado pela própria família dos bolsistas: nos três cursos, eles recorreram principalmente à ajuda de parentes, opção marcada por 48\% $(n=78)$ do total de bolsistas. Através das entrevistas, ficou claro que, além da ajuda financeira para permanência do bolsista na instituição, este apoio também se refere ao incentivo familiar dado ao bolsista para continuar os estudos.

A PUC-Rio também ocupa um lugar importante no suporte dado aos bolsistas, tendo sido a segunda esfera de apoio mais procurada pelos estudantes do ProUni (29\%, ou 47 casos), principalmente entre os de Psicologia (40\%, ou 16 casos). Ajuda de outros bolsistas aparece em terceiro lugar, alternativa escolhida por 25\% $(n=41)$ dos alunos de nossa amostra. Segundo os entrevistados, os próprios bolsistas se reúnem para estudar ou revisar matérias, e, algumas vezes, há troca de livros entre bolsistas de períodos mais adiantados e os que se encontram nos primeiros anos da graduação.

É interessante perceber que a proporção de alunos que afirmaram ter recorrido a não bolsistas, apenas 7\%, ou 11 bolsistas, é inferior à alternativa "amigos fora da faculdade", escolhida por $24 \%$ ou 39 alunos. Na graduação de Psicologia, apenas 2,5\% ou 1 bolsista procurou alunos não bolsistas ante suas dificuldades. Reafirma-se, dessa forma, a existência de certo distanciamento entre o grupo de bolsistas e o de não bolsistas. Esta parece ser a tendência também em relação ao contato com os professores: apenas $16 \%$ ou 26 estudantes tendo recorrido a eles. Entre os bolsistas de Administração, grupo com as maiores dificuldades acadêmicas, somente $18,4 \%$ ou 7 bolsistas buscaram ajuda junto ao corpo docente, sugerindo que as atividades de monitoria são o principal meio de solucionar suas dúvidas. Estes dados sugerem que os bolsistas contam mais com os colegas e monitores para solucionar suas dúvidas do que com os professores. Por fim, aqueles que afirmaram não ter procurado ajuda somam 11\% $(n=18)$ e $8,6 \%(n=14)$ recorreram a outros tipos de ajuda, como a de amigos de trabalho.

\section{Considerações finais}

As políticas de ações afirmativas no ensino superior brasileiro têm início no ano de 2001, e ainda hoje suscitam defesas e críticas acaloradas sobre sua contribuição para a redução das desigualdades existentes em nosso país. Como vimos, apesar da dimensão do ProUni, a pesquisa sobre seus beneficiários ainda é incipiente. Este trabalho pretendeu, dessa forma, contribuir para caracterizar socioeconomicamente os bolsistas de três cursos da PUC-Rio, comparando-os com o perfil dos estudantes

${ }^{8}$ A pergunta possuía oito alternativas, e era possível marcar que esta IES tradicionalmente seleciona. Em um segundo momento, analisamos os principais aspectos da inserção desses bolsistas, suas 
dificuldades e auxílios recebidos, relações entre bolsistas e não bolsistas e os principais atores que ajudaram neste processo.

Os dados coletados pela pesquisa permitem afirmar que os beneficiados pelo ProUni nos cursos de Administração, Direito e Psicologia pertencem a grupos de cor, classe social, renda e origem escolar pouco representados no ensino superior e, especialmente, nas instituições de reconhecida qualidade acadêmica. Ressalte-se que o programa proporcionou a entrada de uma clientela social bastante distinta daquela que tradicionalmente ingressa nesses cursos.

Essa diferença social entre os estudantes é vivida de forma intensa pelos bolsistas de nossa amostra, havendo mesmo um distanciamento entre alunos bolsistas e não bolsistas. Contudo, o fato de não existir uma maior interação entre os dois grupos não é interpretado enquanto práticas de discriminação social ou racial por parte dos alunos pagantes, mas sim como resultado da percepção das desigualdades de origem social existentes entre eles e de identificação com outros bolsistas.

A existência de uma estrutura de apoio aos estudantes pobres anterior à implantação do ProUni se mostrou fundamental para garantir a permanência dos bolsistas participantes do Programa. Os diversos auxílios oferecidos pelo Fesp resolvem (ou, pelo menos, amenizam em muito) um dos principais problemas enfrentados com a entrada no ensino superior, a questão financeira, e permitem a dedicação aos estudos. Por outro lado, as dificuldades vivenciadas no início do curso por aqueles que não são contemplados por esses benefícios evidenciam que uma política de acesso de estratos mais baixos da população ao ensino superior deve ser acompanhada por medidas de suporte ao estudante durante sua vida universitária, para garantir uma formação de qualidade e a conclusão do curso.

Isso significa garantir também a qualidade das instituições nas quais esses estudantes estão ingressando e investigar como se processa a vivência acadêmica quando não se possui acesso a mecanismos de manutenção financeira ou de apoio acadêmico. Evidencia-se, assim, a necessidade de mais estudos que venham a esclarecer tais questões, contribuindo para sabermos em que extensão o ProUni contribui para a democratização da educação superior em suas várias dimensões: acesso, permanência e situação dos egressos.

\section{Referências bibliográficas}

BRANDÃO, André A. Cotas raciais no Brasil: a primeira avaliação. Rio de Janeiro: DP\&A, 2007.

BRASIL. Projeto de Lei n 3.582, de 28 de abril de 2004. Dispõe sobre a instituição do Programa Universidade para Todos (ProUni). Disponível em: < http://www.asduerj.org.br/documentos/pdf/

Substitutivo_10_08_04.pdf>. 
BRASIL. Lei $n^{\circ} 11.096$, de 13 de janeiro de 2005. Institui o Programa Universidade para Todos (ProUni), regula a atuação de entidades beneficentes de assistência social no ensino superior, altera a Lei ${ }^{\circ}$ 10.891, de 9 de julho de 2004, e dá outras providências. Disponível em: <http://www2.camara.gov.br/legin/fed/lei/2005/lei-11096-13janeiro-2005-535381-norma-pl.html>. Acesso em: 10 jun. 2008.

CARVALHO, Cristina Helena. O ProUni no Governo Lula e o jogo político em torno do acesso ao ensino superior. Educação \& Sociedade, Campinas, v. 27, n. 96, p. 979-1000, 2006.

Disponível em: <http://www.scielo.br/scielo.php?script=sci arttext\&pid $=$ S0101-73302006000300016\&lng $=$ en\&nrm $=$ iso $>$. Acesso: 23 ago. 2009.

CATANI, Afrânio M.; HEY, Ana Paula; GILIOLI, Renato de Sousa P. ProUni: democratização do acesso às instituições de ensino superior? Educar em Revista, Curitiba, n. 28, dez. 2006. Disponível em: < http://www.scielo. br/pdf/er/n28/a09n28.pdf>.

DAUSTER, Tania. "Uma revolução silenciosa": notas sobre o ingresso de setores de baixa renda na universidade. Trabalho apresentado no VIII Congresso Luso-Afro- Brasileiro de Ciências Sociais. 2004. Disponível em: < http://www.ces.uc.pt/lab2004/pdfs/TaniaDauster.pdf>.

FACEIRA, Lobelia da Silva. O ProUni como política pública em suas instâncias macro-estruturais, meso-institucionais e microssociais: pesquisa sobre sua implementação pelo MEC e por duas universidades da Região Metropolitana do Rio de Janeiro. 2009. Tese (Doutorado em Educação) - Pontifícia Universidade Católica do Rio de Janeiro (PUC-Rio), 2009. Disponível em: < http://msu. dominiotemporario.com/doc/TeseLOBELIA.pdf $>$.

\section{INSTITUTO BRASILEIRO DE GEOGRAFIA E ESTATÍSTICA (IBGE).}

Síntese de Indicadores Sociais: uma análise das condições de vida da população brasileira 2009. Rio de Janeiro, 2009. Disponível em: <http://biblioteca.ibge.gov.br/visualizacao/monografias/GEBIS\%20-\%20 $\mathrm{RJ} /$ sintese_indic/indic_sociais2009.pdf $>$.

INSTITUTO NACIONAL DE ESTUDOS E PESQUISAS EDUCACIONAIS ANÍSIO TEIXEIRA (INEP). Relatório de IES: Pontifícia Universidade Católica do Rio de Janeiro, Exame Nacional de Desempenho dos Estudantes, 2006. Disponível em: <http://enade.inep.gov.br/ enadeResultadoPDF/2006/relatorio/ies/05283304557.pdf>. Acesso em: 20 nov. 2009.

PASTORE, José; SILVA, Nelson do Valle. Mobilidade social no Brasil. São Paulo: Makron Books, 2000. 
PEIXOTO, Maria do Carmo de L.; ARANHA, Antônia Vitória (Orgs.).

Universidade pública e inclusão social: experiência e imaginação. Belo Horizonte: UFMG, 2008.

RETRATOS do Brasil: entre as particulares, PUC-Rio se destaca em $1^{\circ}$ lugar. O GLOBO [jornal], Rio de Janeiro, $1^{\circ}$ set. 2009.

RISTOFF, Dilvo. A universidade brasileira contemporânea: tendências e perspectivas. In: MOROSINI, Marilia (Org.). A universidade no Brasil: concepções e modelos. Brasília: Inep, 2006.

RODRIGUES, Bianca A. C. "Passar é fácil, continuar é que é difícil...": a permanência de alunos bolsistas da PUC-Rio. 2008. Dissertação (Mestrado em Serviço Social) - Pontifícia Universidade Católica do Rio de Janeiro (PUC-Rio), 2008.

SANTOS, Sales Augusto dos (Org.). Ações afirmativas e combate ao racismo nas Américas. Brasília: MEC, 2005.

Clarissa Tagliari Santos é mestranda do Programa de Pós-Graduação em Sociologia e Antropologia da Universidade Federal do Rio de Janeiro (UFRJ).

clarits@uol.com.br

Recebido em 20 de abril de 2011.

Aprovado em 18 de abril de 2012. 